\title{
Geomagnetic investigation of mineral rocks at Awo, Osun state, southwest Nigeria
}

\author{
OJO, Akintayo O. ${ }^{1 *}$, POPOOLA, O. I. ${ }^{2}$ \\ ${ }^{I}$ Department of Physics, Osun State College of Education, Ilesa, Nigeria \\ ${ }^{2}$ Department of Physics, University of Ibadan, Ibadan, Nigeria \\ *Corresponding author E-mail: akintayoojo@yahoo.com
}

\begin{abstract}
A ground magnetic study was carried out to identify the locations and depths of formation of different magnetic minerals at Awo town, Egbedore local government area of Osun State, Southwest Nigeria. On the study area, ten magnetic traverses were occupied with 10m spacing in between each traverses and $10 \mathrm{~m}$ station intervals. The traverses were 100m long orientated in East - West direction. After correcting the magnetic data for the effect of drift and regional magnetic variation of the study area, the calculated magnetic anomalies were used in plotting the 3D view maps, and carrying out forward and inverse calculations (3D inversion) of the subsurface of the study area using MAG3D inversion program. The interpretation of each profile (traverses) and 3D inversion shows variable anomaly, which is indicative of contrast in the susceptibility of the subsurface. The results possibly suggest that mineral rocks with high magnetic susceptibility values (between 7.15 and 4.72) such as Columbite and Tantalite were buried from the centre towards the south western region of the study area at depth between $20 \mathrm{~m}$ and $90 \mathrm{~m}$; while mineral rocks with low magnetic susceptibility values (between -7.40 and -5.00 ) such as Sandstone, Quartz and Calcite were harboured at the north western region at depth between $75 \mathrm{~m}$ and $100 \mathrm{~m}$. More than fifty percentage of the volume has an intermediate magnetic susceptibility values (between - 4.00 and 4.00 ) indicating that the region is predominantly a schist pegmatite vein that probably contains mineral deposits such as Beryl, Tourmaline and Mica in both disseminated and massive quantities.
\end{abstract}

Keywords: Awo town, magnetic minerals, magnetic susceptibility, 3d views maps, 3 d inversion.

\section{Introduction}

The surface of the earth has provided the setting for most of human endeavours throughout the history of civilization, and these activities have been profoundly affected by the largely invisible characteristics of the immediate subsurface. Human development has depended heavily on resources obtained from both near surface (as in construction materials) and from hundreds to thousands of meters deep (as in metallic ores and petroleum based products). In relation to these activities, subsurface characteristics of particular interest to earth scientists include the location and depth of mineral rocks, distribution and structure of rock types, grain size and material strength, porosity and permeability, to name a few (Olowofela et al. 2012).

Geophysicists have long recognized the need for inverting their data. The data need to be inverted to generate a distribution of the physical property. The state of computing resources a few decades ago meant that even the best inversion algorithms could recover estimates for only a small number of parameters. Consequently, the subsurface was modelled as a few layers, or as simple prismatic objects, and parameters were adjusted so that numerically modelled data fit the observations as well as possible. Unfortunately, earth structures are generally much more complicated and hence incorrect conclusions were often drawn ( $\mathrm{Li} \&$ Oldenburg 1996, 2003).

Mineral exploration and engineering organizations now routinely apply modern inversion techniques to geophysical surveys instead of applying ad-hoc methods to the interpretation of raw or filtered data. Geoscientists can now produce a range of acceptable subsurface models based upon rigorous and well defined criteria. The value added through the provision of well constrained, easily visualized 2D and 3D models of subsurface physical properties means that geophysical surveying can be more cost effective, allowing decision makers to act with more confidence in assessing the risks and costs of projects requiring subsurface information (Lelievre \& Oldenburg 2006).

Magnetic field data are of fundamental importance in many areas of geophysical exploration with magnetic 3D inversion being a common aid to their interpretation. In the majority of magnetic based inversions, it is assumed that the magnetic response arises entirely from magnetic induction. This paper presents a method to invert magnetic anomaly data in a variety of non - complex contexts. The inverse problem seeks to find a model that would give a response similar to the actual field data, subject to certain restrictions. The model, whose parameters are the physical quantities or properties that we seek to estimate, is an idealized mathematical representation of the earth. The choice of the model parameters is largely dependent on the nature of the geophysical problem to be solved. The model response is the synthetic data that can be calculated from a relation that defines the model for a given set of model parameters (Li \& Oldenburg 1998, 2003).

In geomagnetic susceptibility imaging, the model parameters are the model susceptibility values with depths and the data are the measured total magnetic field values. The observed and theoretical responses are matched with the use of suitable optimization algo- 
rithms which are designed to minimize some measures of the difference between the observed and computed responses. Usually, an initial model (a skilled guess model) is modified in an iterative procedure so that the difference between the model response and the observed data values can be minimized (Li \& Oldenburg 1998, 2003). The model parameters are updated using a linear iterative adjustment procedure (Constable et al. 1987, Al - chalabi, 1971). In this study, geomagnetic data obtained on the study area were used to identify the location and depth of formation of different magnetic minerals (such as Beryl, Mica, Tantalite, Tourmaline, Columbite and so on) in the study area.

\section{Geological characteristics of the study area}

The study area, Awo town, Egbedore Local Government, Osun State, Southwest Nigeria is bounded by Latitudes $7.76934^{\circ} \mathrm{N}$ to $7.77090^{\circ} \mathrm{N}$ and Longitudes $4.40431^{\circ} \mathrm{E}$ to $4.40560^{\circ} \mathrm{E}$, and it is on a schist pegmatite vein (fig. 2) characterized predominantly by Beryl, Tourmaline, Feldspar, Coltan and Mica which were found in grains scattered on the ground surface, larger samples excavated by artisan miners were found around the study area.

The study area lies within the crystalline basement complex of south western Nigeria and is underlain by Precambrian rocks (fig. 1) (Rahaman 1976). The main rock types found in this area are amphibolites complex, migmatite and Granitic gnesiss, quartzite, metaigneous rocks; Charnockitic; Gabbroic and Diorite; and the members of the older Granite suite mainly Granites, Granodiorites, Syenites and schist. Most part of the area occupying quartzite and quartz schist also form part of the rock units (Adekoya et al. 2003, Ajayi \& Ogedengbe 2003, Kayode 2006, Folami 1992).

Minor rock types are found within the Gneisses and older Granites. The minor rock types include pegmatite composed of Microcline and Quartz, which are wide spread throughout the crystalline basement complex of south western Nigeria. The pegmatite are however, conspicuously absent from the main area of the slightly Migmatised to unmagmatised para-schists and metaigneous rocks. The pegmatite in the Gneisses may be conformable but they are more commonly cross cutting. The Quartz veins and lenses occur in all the major rock types of the basement complex and they are small varying in thickness from a few millimetres to a metre (Kayode 2006). They show great irregularities in their form and are seen in places to thin out widen or turn in their course. Dolente dykes are also associated with the Gneisses and older Granites, occurring as tabular, unmetamorphosed bodies cross cutting the foliation in the host rocks and are regarded by Rahaman (1976) as the youngest member of the basement complex. They range in thickness from about a few millimetres to half a metre. They trend northeast to southwest and east-northeast to west-southwest (Okunlola \& Ofonime 2006).

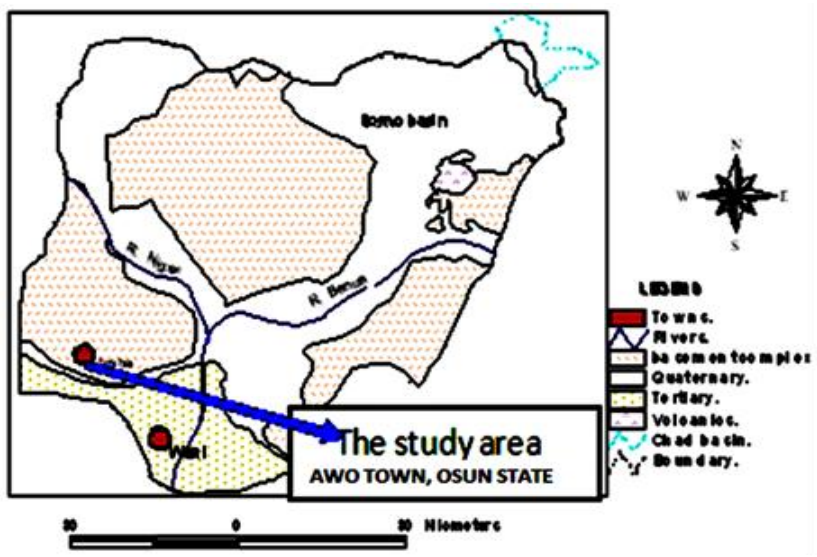

Fig. 1: Map of Nigeria Showing the study area.

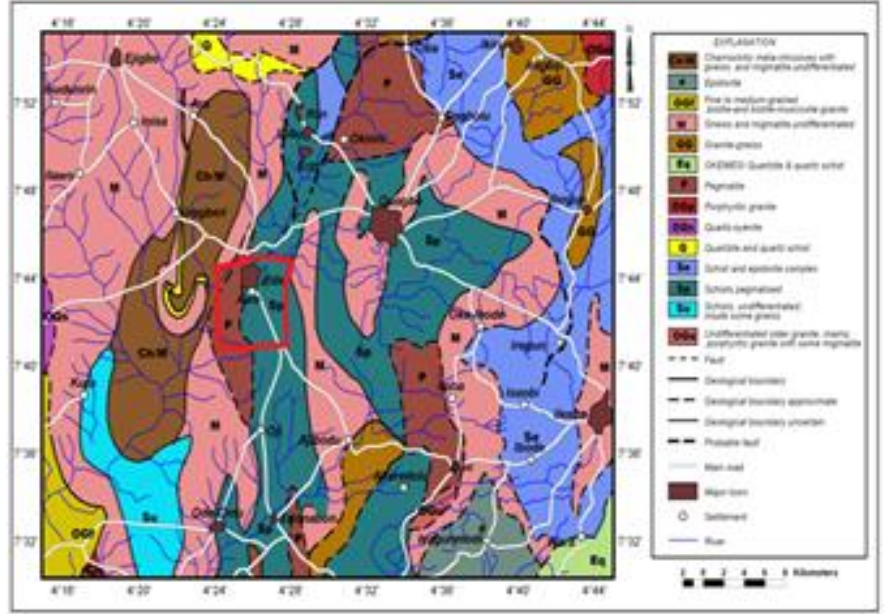

Fig. 2: Geological Map of Osun State, Southwest Nigeria showing the study area.

\section{Theory}

\subsection{Magnetic method}

The origin of the earth's magnetism is commonly believed to be the liquid core, which cools at the outside as a result of which material becomes denser and sinks towards the inside of the outer core and new warm liquid matter rises to the outside, thus, convection currents are generated by liquid metallic matter which move through a weak cosmic magnetic field which subsequently generates induction currents (Nettleton 1976). It is this induction current that generate the earth's crust magnetic field (Telford, et al. 1990). Most rocks of the earth's crust contain crystals with magnetic minerals, thus most rocks have a certain amount of magnetism which usually has two components induced by the magnetic field present while taken measurement, and remnant which formed during geologic history (Reijers 1996).

However, the ground magnetic study is used for detail mapping in order to understand the subsurface geology of an area. The technique requires measurements of the amplitude of magnetic components at discrete points along traverses distributed regularly throughout the survey area of interest. In ground magnetic study, three components are measured which are horizontal, vertical and total components. The vertical components and the total components are mostly used in the past studies to delineate faults, fractures, depth to magnetic basement and other geological structures (Folami 1992).

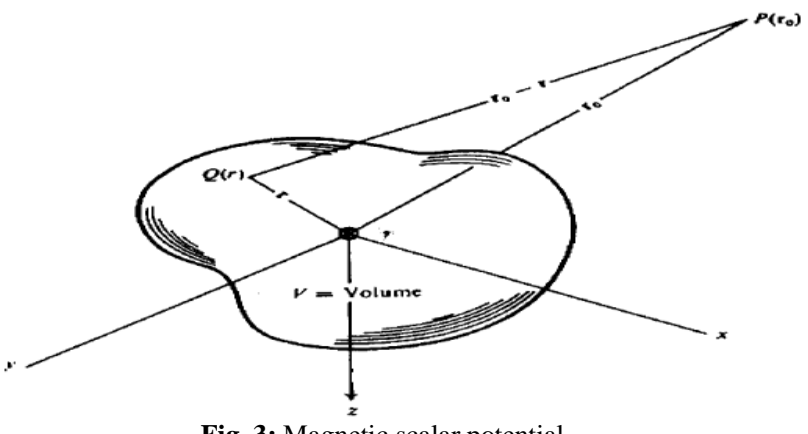

Fig. 3: Magnetic scalar potential.

The magnetic scalar potential due to a continuous distribution of matter e.g. earth may be calculated at an external point P (fig. 3) (Telford et al. 1990, Parasnis 1978). If the materials that fills the volume $\mathrm{V}$ has a continuous distribution of magnetic dipole moment per unit volume, then: 


$$
\vec{j}=\frac{\vec{m}}{\vec{v}}
$$

But the magnetic potential $\mathrm{A}$ of a dipole at point $\mathrm{P}$ outside the volume $\mathrm{V}$ and whose moments is $\mathrm{m}$ given by;

$A=\frac{m \cos \theta}{r^{2}}-\vec{m} \cdot \vec{\nabla}\left[\frac{1}{r}\right]$

Integrating equation (2) gives:

$$
A=-\int_{V} \vec{J} \cdot \vec{\nabla}\left|\frac{1}{\overrightarrow{r-r_{0}}}\right| d v
$$

But $d v=d^{3} r_{0}$

$$
A=-\int_{V} \vec{J} \cdot \vec{\nabla}\left|\frac{1}{\vec{r}-r_{0}}\right| d^{3} r_{0}
$$

The total magnetic field intensity at point $\mathrm{P}$ outside the volume $\mathrm{V}$ is given as:

$$
\vec{H}=-\vec{\nabla} A
$$

Putting equation (4) in (5) it gives:

$$
\vec{H}=\vec{\nabla} \int_{V} \vec{J} \cdot \vec{\nabla}\left|\frac{1}{\vec{r}+\vec{r}}\right| d^{3} r_{0}
$$

Assuming the direction of magnetization is the same throughout the volume, $V d r$ then:

$\vec{J} \cdot \vec{\nabla}=J \frac{d}{d r}$

Putting equation (7) in (6) gives;

$$
\vec{H}=\vec{\nabla} \frac{d}{d r} \int_{V} J\left|\frac{1}{\mid \vec{r}-\overrightarrow{r_{0}}}\right| d^{3} r_{0}
$$

Gauss however, expresses the volume integral in terms of the surface integral given by:

$$
\int_{V} \vec{V} \cdot \vec{F} d V=\int \vec{F} \cdot \hat{n} d A
$$

If the point $\mathrm{P}$ is outside the volume, it implies that surface $\mathrm{S}$ encloses no attractive mass, and then the right hand side of equation (9) is zero. Hence:

$$
\int_{V} \vec{\nabla} \cdot \vec{F} d^{3} r_{0}=0
$$

Differentiating equation (10), we have:

$$
\vec{\nabla} \cdot F=0
$$

Taking $\vec{H}$ as the function, the equation becomes:

$$
\vec{\nabla} \cdot \vec{H}=0
$$

Putting equation (5) in (12), we have:

$$
\begin{aligned}
& \vec{\nabla} \cdot \vec{\nabla} \cdot A=0 \\
& \vec{\nabla}^{2} \cdot A=0 \\
& \therefore \frac{\partial^{2} A}{\partial x^{2}}+\frac{\partial^{2} A}{\partial y^{2}}+\frac{\partial^{2} A}{\partial z^{2}}=0
\end{aligned}
$$

If $\mathrm{P}$ is enclosed within the volume $\mathrm{V}$, the magnetic potential $\mathrm{A}$ becomes:
$A=-\int_{V-V^{1}} \vec{J} \cdot \vec{\nabla}\left|\frac{1}{\vec{r}-\overrightarrow{r_{0}}}\right| d^{3} r_{0}-\int_{V^{1}} \vec{J} \cdot \vec{\nabla}\left|\frac{1}{\vec{r}-\vec{r}_{0}}\right| d^{3} r_{0}$

The first term is non-singular, therefore it is harmonic everywhere. $\mathrm{J}$ may be made constant by making a small enough in the second term.

$A=-\int_{V^{1}} \vec{\nabla} \cdot \vec{J} \cdot \vec{\nabla} \cdot \vec{\nabla}\left|\frac{1}{\vec{r}-\vec{r}_{0}}\right| d^{3} r_{0}$

From Gauss theorem, equation (17) becomes:

$$
\begin{aligned}
& \vec{\nabla} \cdot A=\int_{S} \vec{\nabla} \cdot \vec{J} \cdot \hat{n} \cdot \vec{\nabla}\left|\frac{1}{\vec{r}-\vec{r}_{0}}\right| d^{3} r_{0} \\
& =-\vec{\nabla} \cdot \vec{J} \int_{S} \frac{\partial}{\partial r} \frac{1}{r} d^{3} r_{0} \\
& =-\vec{\nabla} \cdot \vec{J}\left(-\left(\frac{1}{r}\right)^{2}\right) \int_{S} d^{2} r_{0} \\
& =-\vec{\nabla} \cdot \vec{J}\left(-\left(\frac{1}{r}\right)^{2}\right) 4 \pi\left(r^{n}\right)^{2} \\
& =-\vec{\nabla} \cdot \vec{J} \cdot \frac{4 \pi\left(r^{1}\right)^{2}}{\left(r^{1}\right)^{2}} \\
& \vec{\nabla} \cdot A=4 \pi \vec{\nabla} \cdot \vec{J}
\end{aligned}
$$

Equation (22) is the potential equation within regions occupied by magnetic bodies.

\subsection{Forward and inverse calculations}

After acquiring geophysical data set, it is necessary to model or invert the data set so as to obtain the desired subsurface properties images or distribution. Inversion can be defined as the process of estimating geophysical model parameters of a multi-layered and heterogeneous earth model from observed field data. The observed data can be predicted (forward modelling problem), using the laws of physics relating the model parameters to the observed data. Inversion of observed geophysical data involves the mapping of the geophysical data into the model that will, in some defined sense, best satisfy the measured data and our preconception about the given model. The choice of the model parameters is largely dependent on the nature of the geophysical problem to be solved (Ahzegbobor 2010, Li \& Oldenburg 1998, 2003).

Data from a geophysical experiment can be generically written as $F_{j}[m]=d_{j}+n_{j}$

$j=1, \ldots, N$

Where $F$ is a forward modelling operator that incorporates details of the survey design and the relevant physical equations, $\mathrm{m}$ is a generic symbol for a physical property distribution, and the right hand side represents the observed data $d^{o b s}$ which consist of the true data d plus additive noise $\mathrm{n}$. $\mathrm{F}$ comes in a variety of forms, but most often it is an integral or differential operator, and the resultant equations must be solved numerically (Lelievre \& Oldenburg 2006, Li \& Oldenburg 1996).

For a given inducing field $\vec{B}_{0}$, the magnetization $\vec{J}$ depends upon the susceptibility through a differential equation. However, to the first order approximation when the actual susceptibility is very small, as is most often the case with material encountered in 
mineral explorations, the magnetization $\vec{J}$ is proportional to the susceptibility and is given by the product of susceptibility with inducing magnetic field $\vec{H}_{0}$,

$$
\vec{J}=k \vec{H}_{0}
$$

Where $H_{0}=\vec{B}_{0} / \mu_{0}$ and $\mu_{0}$ is the free space magnetic permeability.

This essentially ignores the self-demagnetization effect by which the secondary field reduces the total inducing field within the susceptible region and results in a weaker magnetization. The anoma-

lous field produced by the distribution of magnetization $\vec{J}$ is given by the following integral equation with a dyadic Green's function,

$$
\vec{B}_{\alpha}(\vec{r})=\frac{\mu_{0}}{4 \pi} \int_{V} \nabla \nabla \frac{1}{\left|\overrightarrow{r-r^{1}}\right|} \cdot \vec{J} d v
$$

Where $\vec{r}$ is the position of the observation point? $V$ represents the volume of magnetization.

The above equation is valid for observation locations above the earth's surface. It is also valid in the boreholes provided we assume that the magnetic permeability is $\mu_{0}$. When the susceptibility is constant within a volume of source region, the above equation can be written in matrix form as

$$
\vec{B}_{\alpha}=\mu_{0}\left(\begin{array}{ccc}
T_{11} & T_{12} & T_{13} \\
T_{21} & T_{22} & T_{23} \\
T_{31} & T_{32} & T_{33}
\end{array}\right) \kappa \vec{H}_{0}
$$

$\vec{B}_{\alpha} \equiv \mu_{0} \kappa T \vec{H}_{0}$

Where $T_{i j}$ is given by

$T_{i j}=\frac{1}{4 \pi} \int_{V} \frac{\partial}{\partial x_{i}} \frac{\partial}{\partial x_{j}} \frac{1}{\left|\overrightarrow{r-r^{1}}\right|} d v$

$i=1,3 ; j=1,3$,

Where $x_{1}, x_{2}$, and $x_{3}$ represent $x, y$, and $z$ respectively.

The expressions of $T_{i j}$ for a cubical source volume can be found in Bhattacharyya (1964). A number of inversion techniques have been used in the interpretation of geophysical data. These include the least-squares, weighted back projection, conjugate gradient, maximum entropy, simulated annealing, artificial neural networks, particle swarm optimization, and singular value decomposition methods (Treitel \& Lines 2001). These techniques can be broadly divided into two groups, the local and global search methods. The local search methods are very simple but require a skilled initial guess solution close to the true model so as to ensure convergence. The global search methods on the other hand are capable of finding acceptable solutions from a wide range of starting set of parameters. However, the global search methods are computationally time intensive (Al - chalabi 1971, Shaw \& Srivastava 2007).

Two procedures, deterministic and stochastic, have been adopted in the inversion of geophysical data. Deterministic inversion procedure searches for model (e.g. spatially varying susceptibility distribution) that gives an acceptable fit to the data and satisfies any prescribed constrained. A common solution minimizes an objective function consisting of a regularized, weighted least squares formulation. The search is typically conducted using iterative, gradient based methods (Ellis \& Oldenburg 1994). Also, stochastic inversion combines observed data, prior information and forward models to produce subsurface models that are most consistent with all available data. A variety of these techniques exist, one approach seek to maximize a specified a posteriori density function of the model parameters (Li \& Oldenburg 1996, 1998, 2003). This approach was modified by Yang \& Labrecque (1999) to allow for a more efficient estimate of the parameter covariance matrix.

\section{Methodology}

The magnetic survey was designed in such a way that deep insight into the magnetic susceptibility contrast in the study area subsurface was delineated. The data acquisition technique requires measurements of the magnetic intensities at discrete points along traverses regularly distributed within the area of interest.

Based on the surface geologic features, an area of $90 \mathrm{~m} \times 100 \mathrm{~m}$ was surveyed. The instruments used for the magnetic survey was the Geometrics Proton Precession Magnetometer (G-856AX Model) with a resolution of $1 \mathrm{nT}$ and Global Positioning System (GPS) to record the coordinates at each station. Measurements were taken along ten traverses with line spacing of $10 \mathrm{~m}$. Each of the $100 \mathrm{~m}$ long traverses has station spacing of $10 \mathrm{~m}$ determined using measuring tape, ropes and pegs. Magnetometer readings were taken at each station and a total of 110 data points were taken on the study area. Repeated readings were made at every thirty minutes at a based station few meters away from the study area to account for the temporal variation in magnetic field. Reoccupation at the base station is to remove the diurnal variation effects of the earth's magnetic field and other sources of external interferences from the data obtained (Kayode 2006). The average of the readings at the base station is then subtracted from each of the data points recorded on the study area to remove drift and diurnal effects. Apart from the diurnal effects, the reductions required for magnetic data are insignificant. The vertical gradient varies from approximately $0.3 \mathrm{nT} / \mathrm{m}$ at the pole to $0.01 \mathrm{nT} / \mathrm{m}$ at the equator. Since the latitude variation is rarely greater than $6 \mathrm{nT} / \mathrm{km}$ (Telfod et al. 1990). The elevation and latitude corrections are considered negligible.

2D maps of the magnetic data before and after subjecting it to drift and diurnal corrections were plotted and, three dimensional contour (anomaly) maps from the corrected magnetic field data relative to the base station against the coordinates along each profile were also plotted. All were plotted using Surfer10 software.

The simplest interpretation is to identify zones with different magnetic characteristics segments of the profiles. Segments with little variation in magnetic characteristics are termed magnetic "quiet" and are associated with rocks with low susceptibilities while segments showing considerable high variation are termed to be magnetically "noisy" and indicate magnetic sources in the subsurface area (Jain 1976, Ishola et al. 2012). Qualitative interpretation relies on the spatial patterns, which can be recognized by the geoscientists. The total component magnetic anomalies are highly variable in shape and amplitude. However, faults, lineaments, dykes, and folds are usually easily identified than features given by some number of sources, which can produce an anomaly that may result in complexities in the interpretations (Kayode \& Adulusi 2010, Folami, 1992, Li \& Oldenburg 1998, Kayode, 2006).

A University of British Columbia (UBC) GIF inversion algorithm, MAG3D (version 4), was used to perform 3D forward modelling and inversion of the magnetic data. Inputs for inversion process were the raw data from the survey and prior knowledge about the study area. The values of the total magnetic field, the inclination and the declination at the centre of the study area (latitude and longitude were calculated using the National Geophysical Data Center's Calculator to be (Declination, Inclination, Ambient field $=$. These are some of the prior knowledge of the study area. 
Inversion constructs 3D model of susceptibility contrast, so interpretation requires an appropriate display for studying the resulting structures. The variation in the susceptibility of the subsurface is displayed in colour which can be matched with the standard susceptibility values of minerals so as to know the possible mineral concentrations.

\section{Results}

Two methods were adopted in this study for presenting magnetic data results. These methods are:

\subsection{Contour map:}

This method was used to produce scaled 2D contour maps before and after drift and diurnal corrections (figures 4 to 13), and scaled $3 \mathrm{D}$ contour maps after the corrections (figures $14-23$ ). Filling the contour plot helps visualize the magnetic field variations in the study area, this greatly aid interpretation.

\subsection{Coloured map:}

Coloured maps are used for plotting raw "total field intensity" data. This is also refers to as $2 \mathrm{D}$ observed magnetic data map (figure 24), it shows the distribution of magnetic anomalies on the study area.

The 3D inversion of the subsurface of the study area (figure 25) and its slices at various depths and locations are shown in figures 26 - 31. An isosurface of the 3D inversion (figure 32) was also generated which shows the regions with the same magnetic susceptibility values.

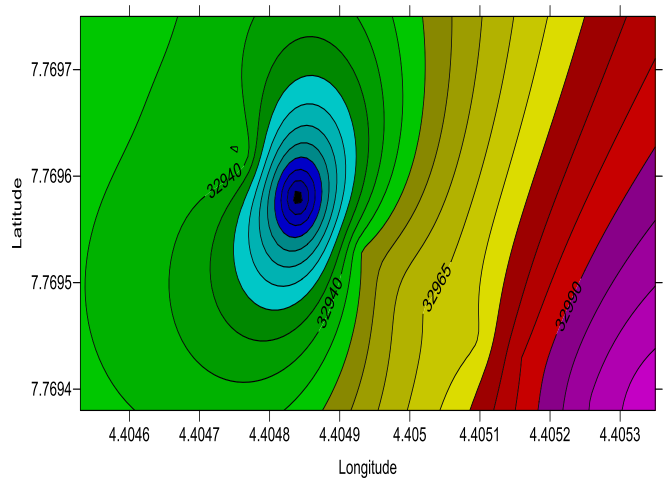

Fig. 4: (a) 2D map of profile 1 before correction

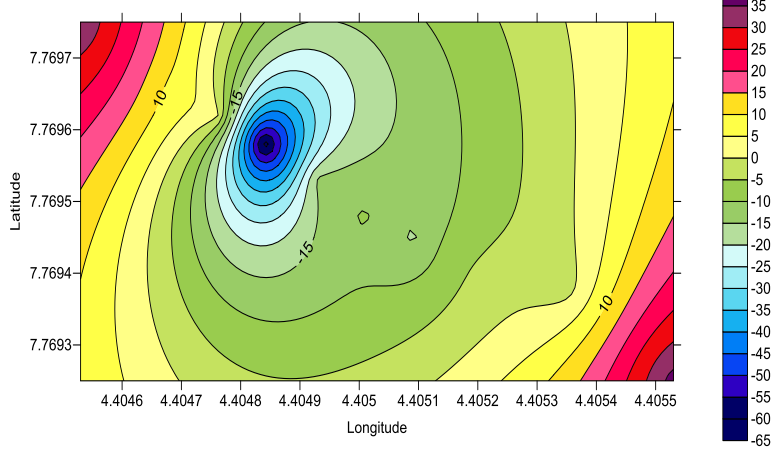

Fig. 4: (a) 2D map of profile 1 after correction

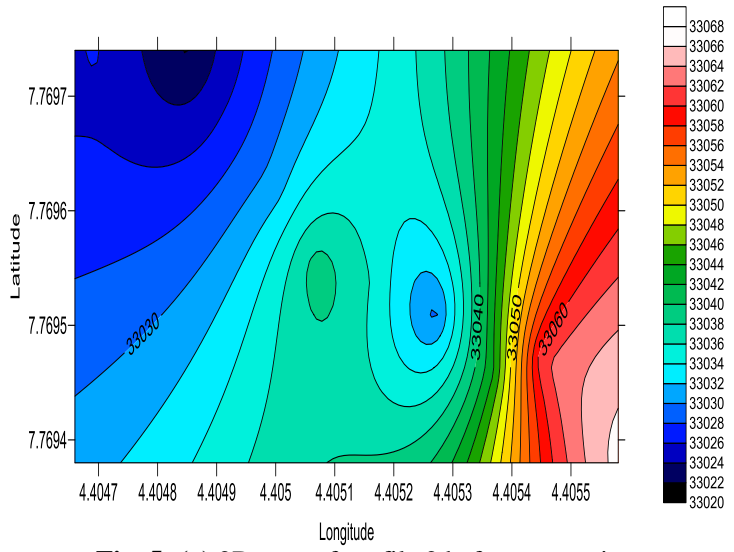

Fig. 5: (a) 2D map of profile 2 before correction
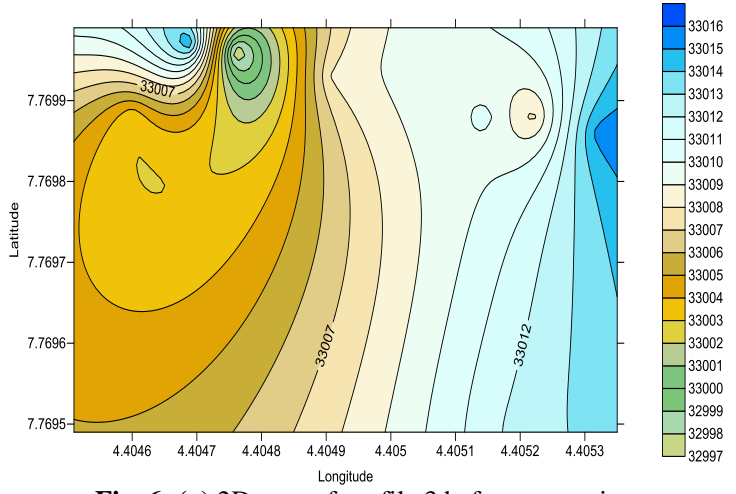

Fig. 6: (a) 2D map of profile 3 before correction

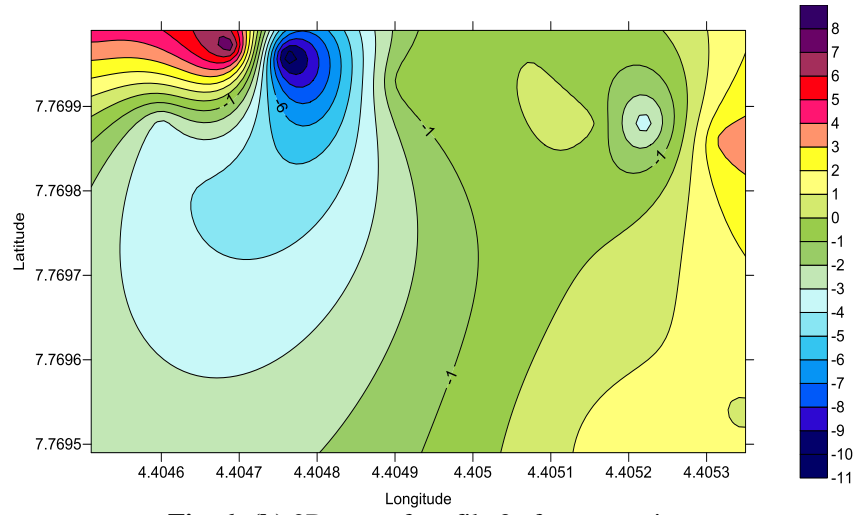

Fig. 6: (b) 2D map of profile 3 after correction

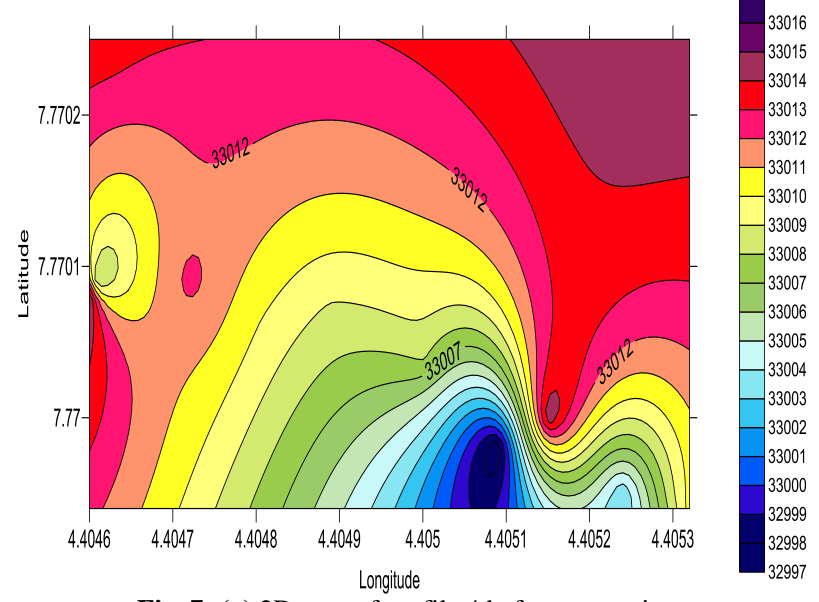

Fig. 7: (a) 2D map of profile 4 before correction. 

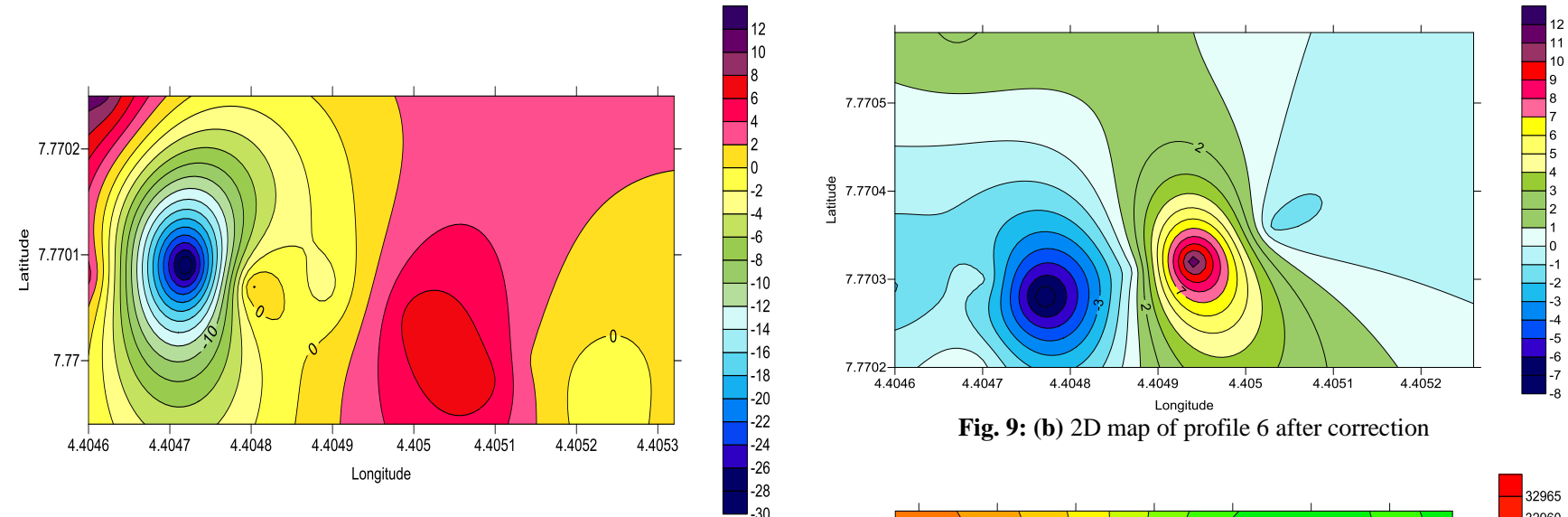

Fig. 7: (b) 2D map of profile 4 after correction
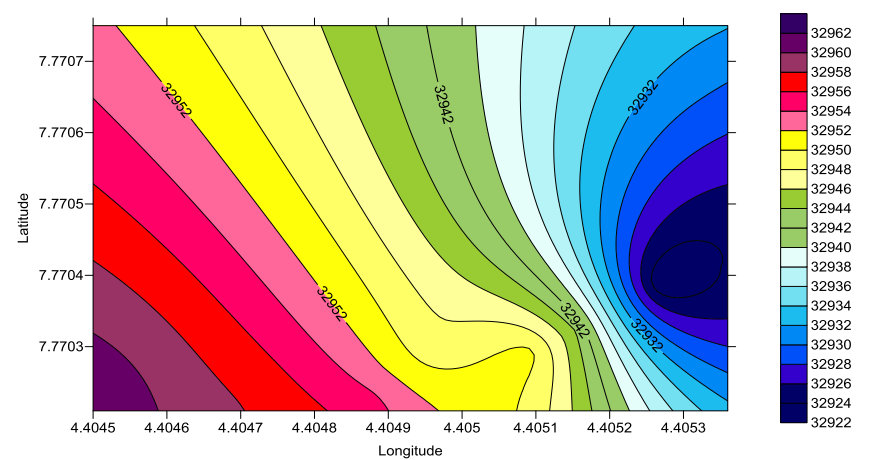

Fig. 9: (b) 2D map of profile 6 after correction

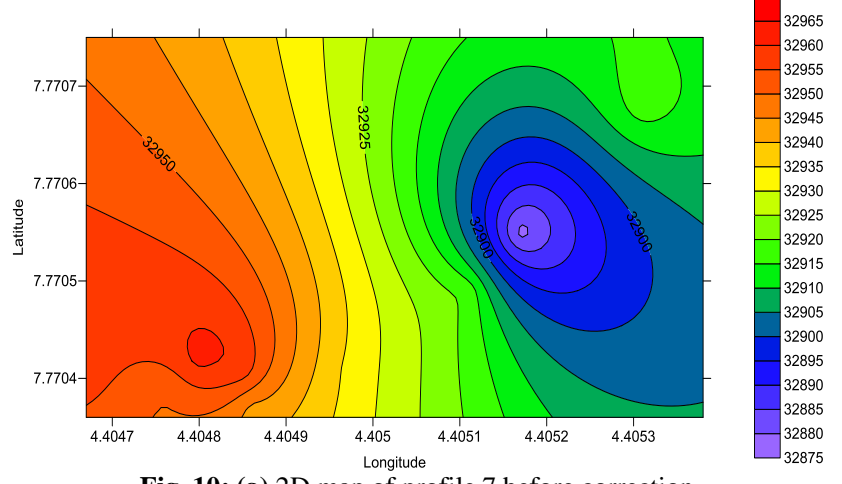

Fig. 8: (a) 2D map of profile 5 before correction
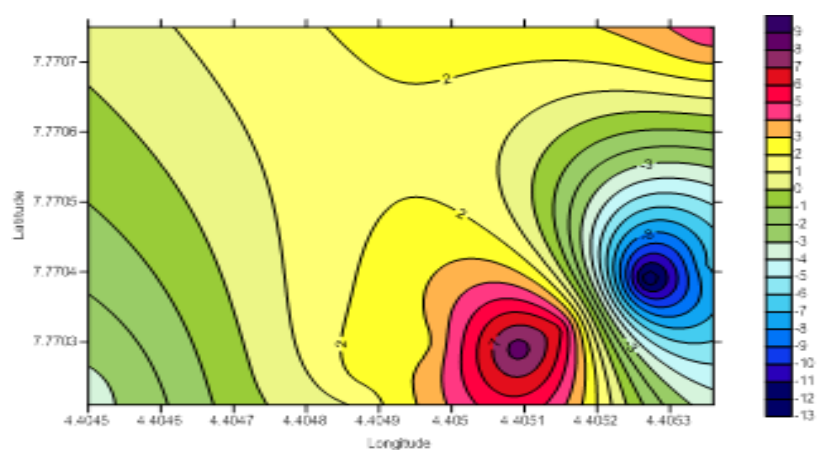

Fig. 8: (b) 2D map of profile 5 after correction.
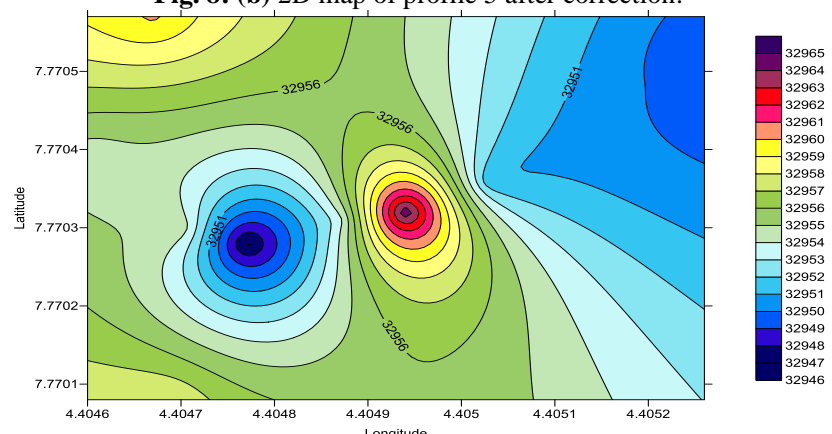

Fig. 9: (a) 2D map of profile 6 before correction
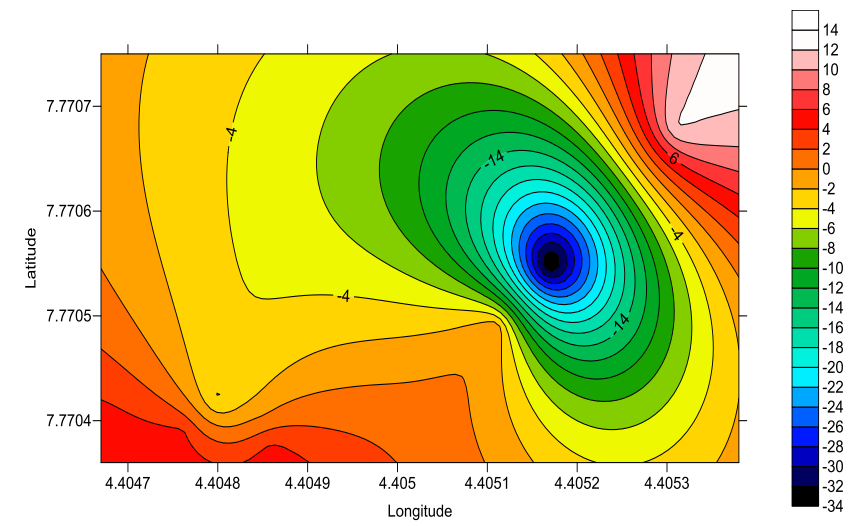

Fig. 10: (b) 2D map of profile 7 after correction

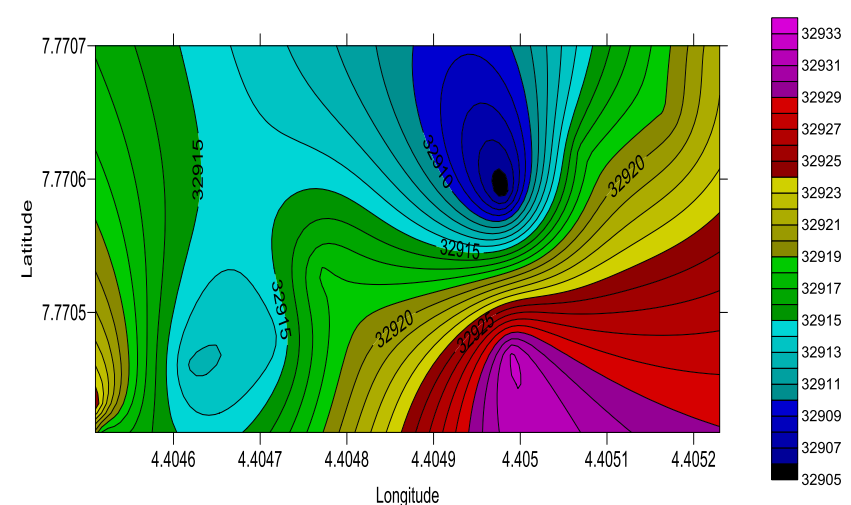

Fig. 11: (a) 2D map of profile 8 before correction 


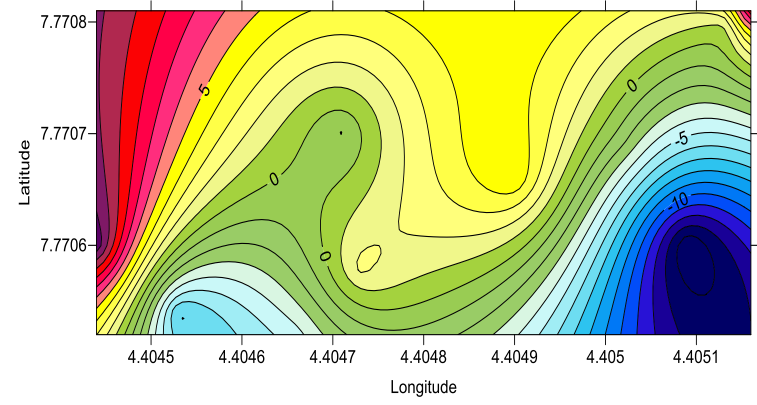

Fig. 12: (b) 2D map of profile 9 after correction

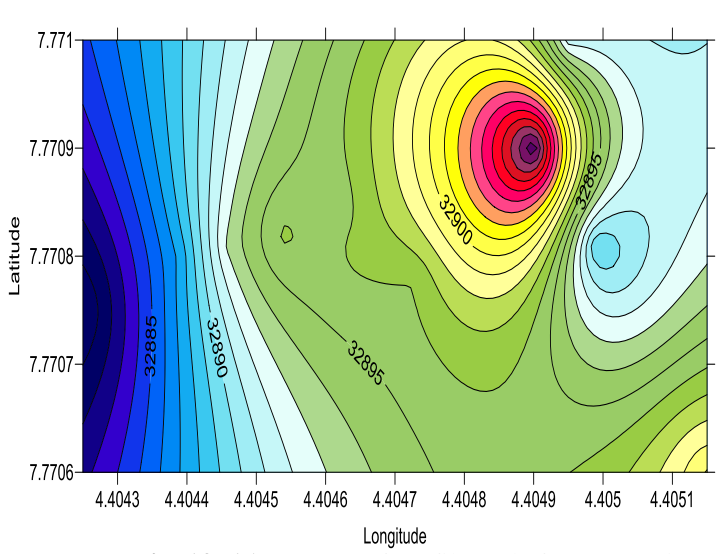

Fig. 13: (a) 2D map of profile 10 before correction

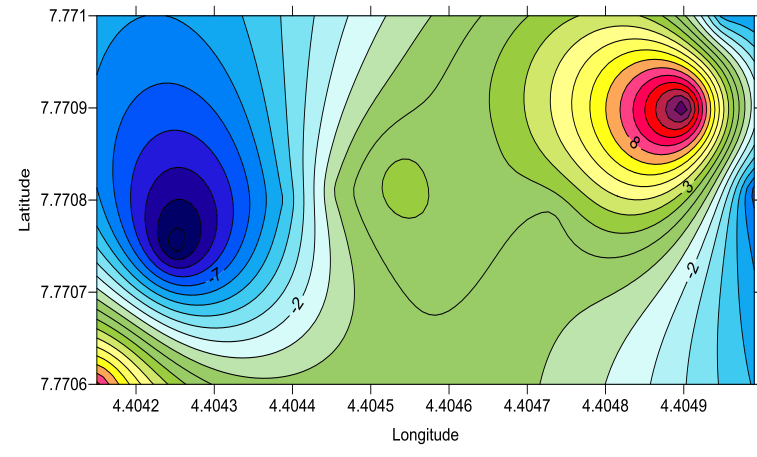

Fig. 13: (b) 2D map of profile 10 after correction
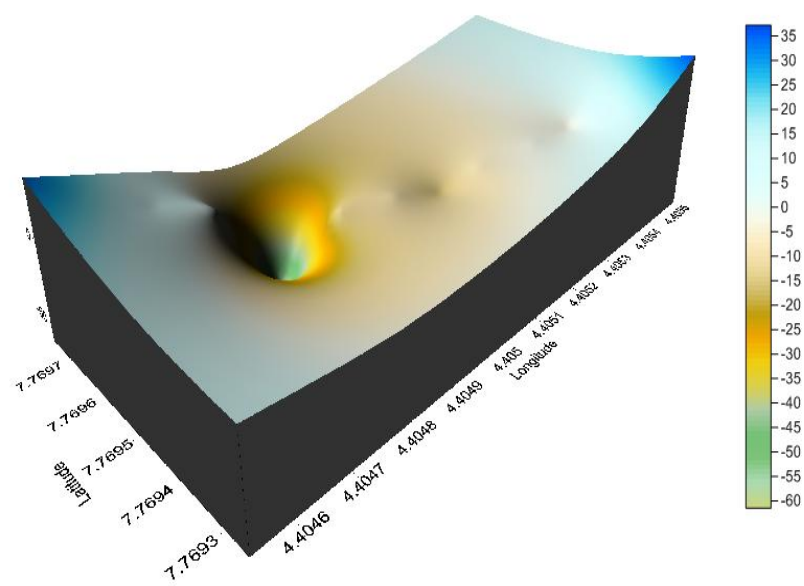
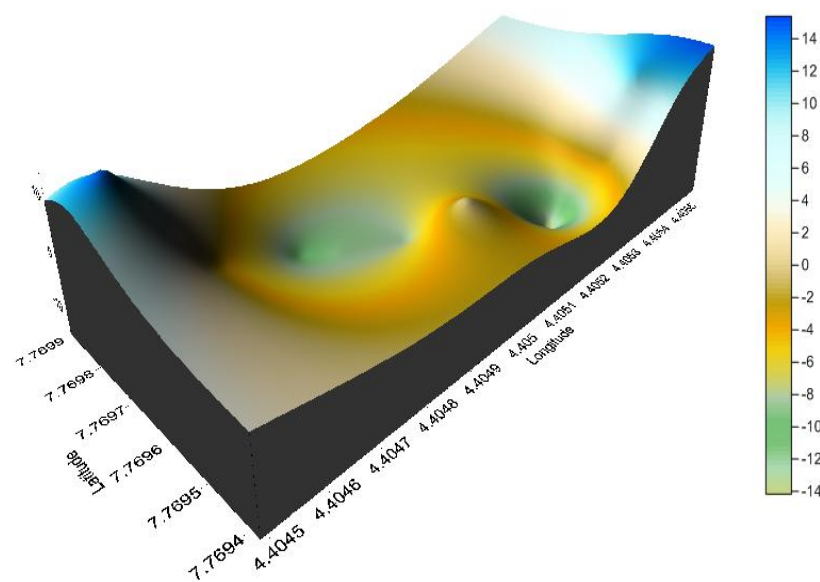

Fig. 15: 3D contour map (nT) of profile 2
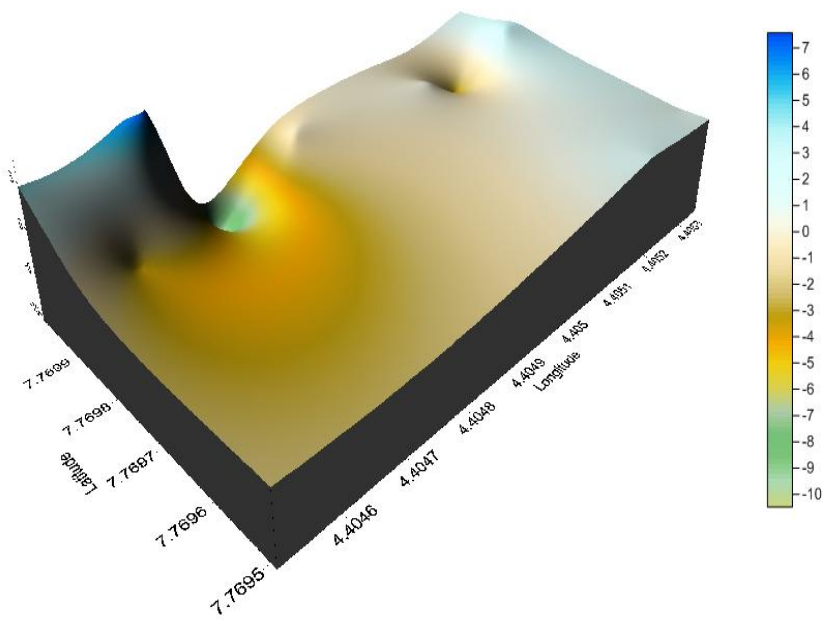

Fig. 16: 3D contour map (nT) of profile 3
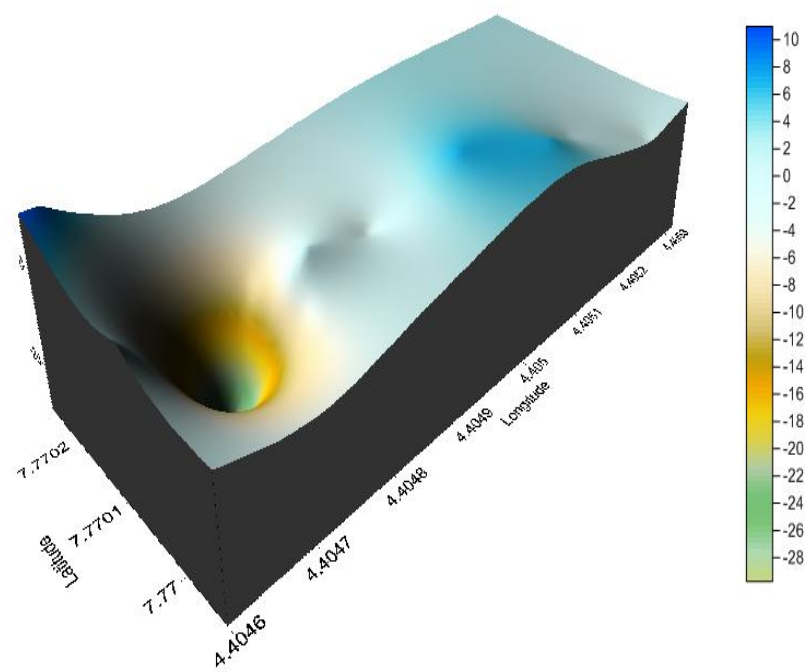

Fig. 17: 3D contour map (nT) of profile 4

Fig. 14: 3D contour map (nT) of profile 1 


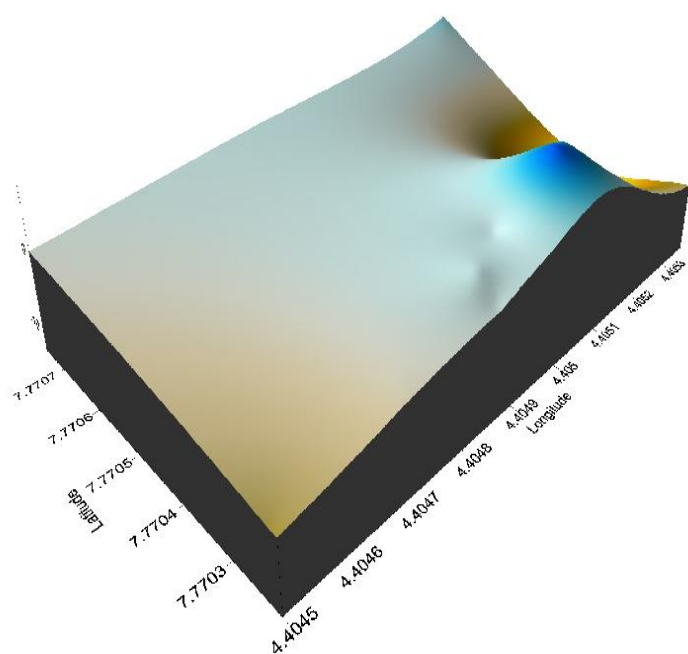

Fig. 18: 3D contour map (nT) of profile 5

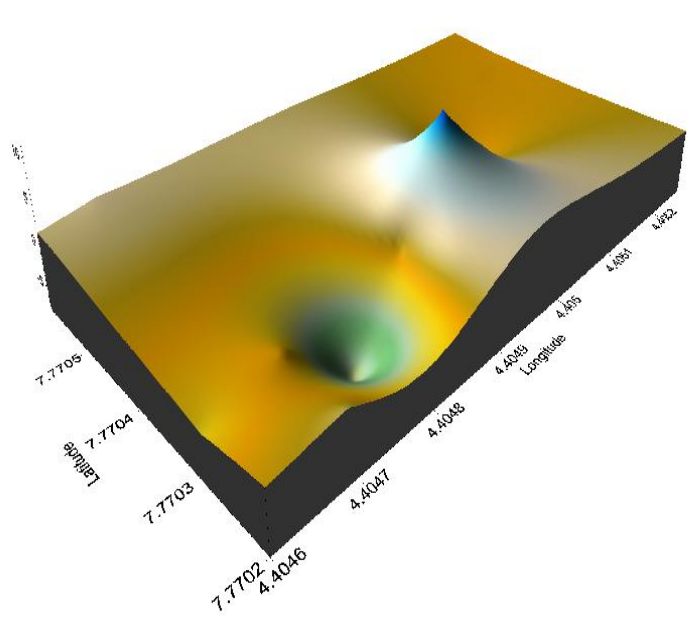

Fig. 19: 3D contour map (nT) of profile 6

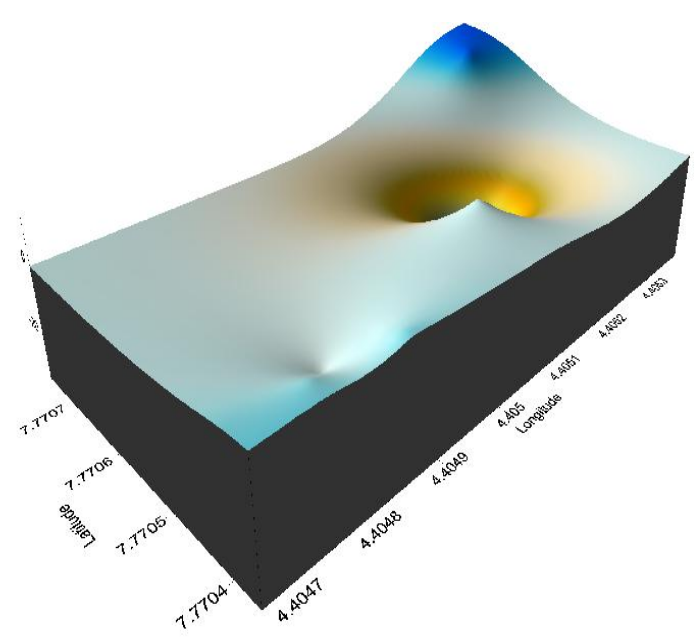

Fig. 20: 3D contour map (nT) of profile 7
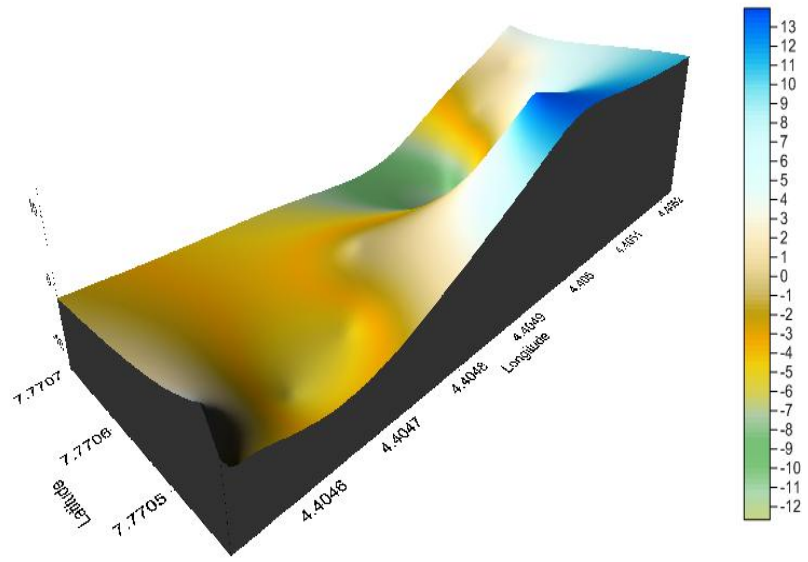

Fig. 21: 3D contour map (nT) of profile 8
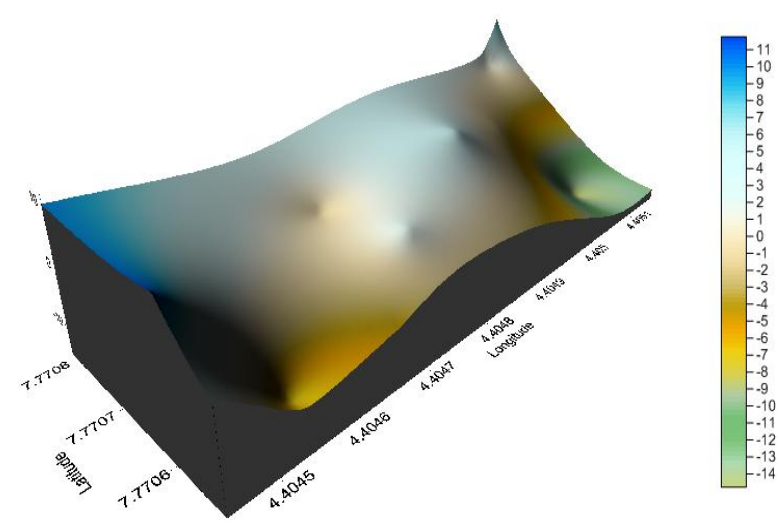

Fig. 22: 3D contour map (nT) of profile 9
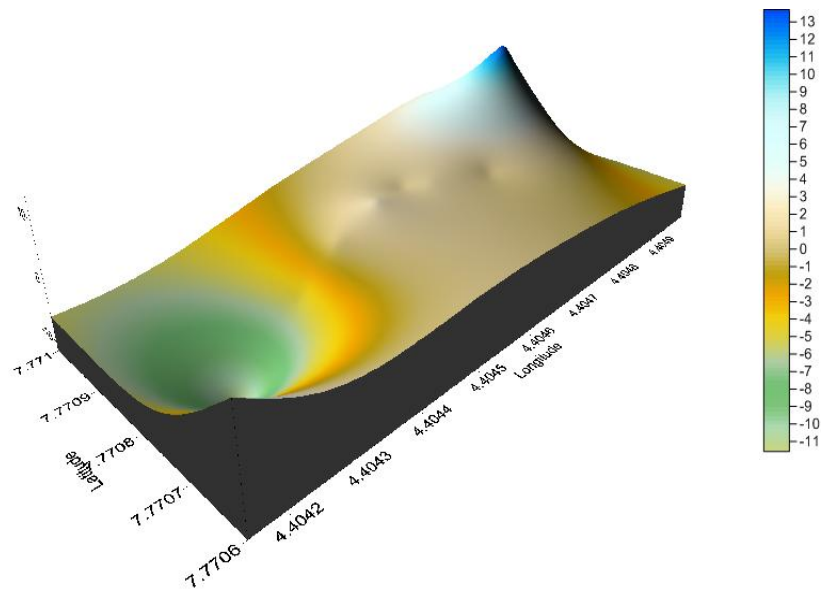

Fig. 23: 3D contour map (nT) of profile 10 


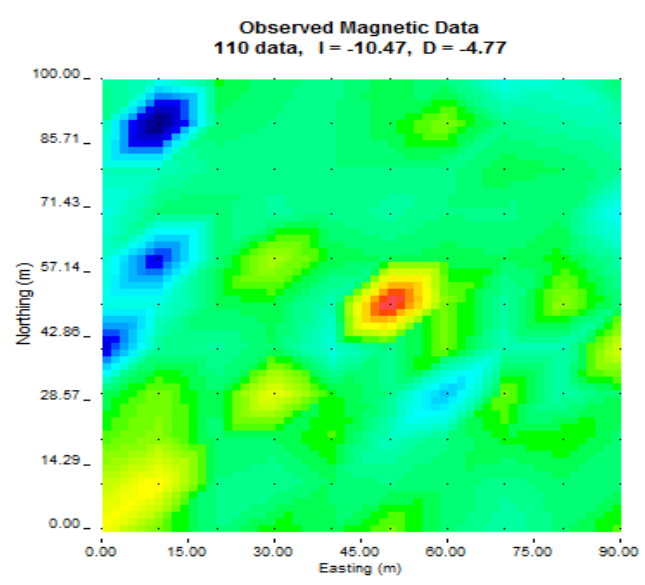

Fig. 24: 2D coloured map showing the magnetic intensity (nT) variation of the study area

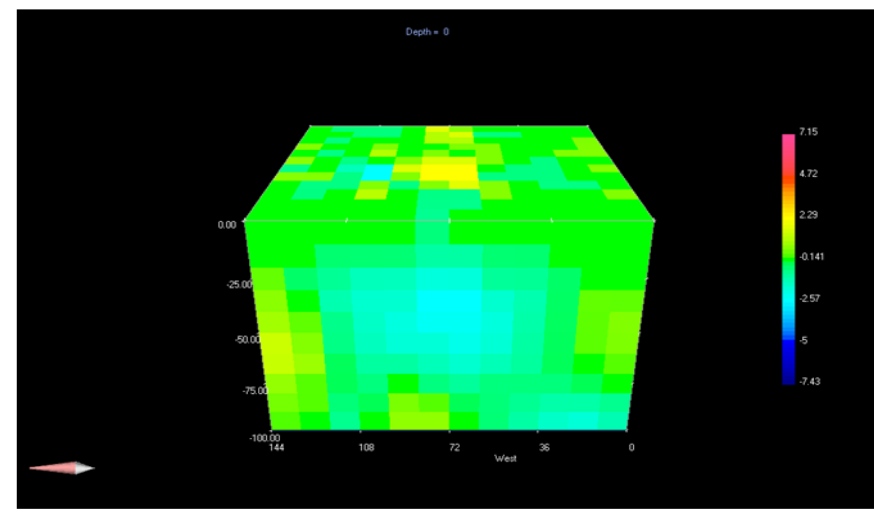

Fig. 25: Recovered 3D inversion / model

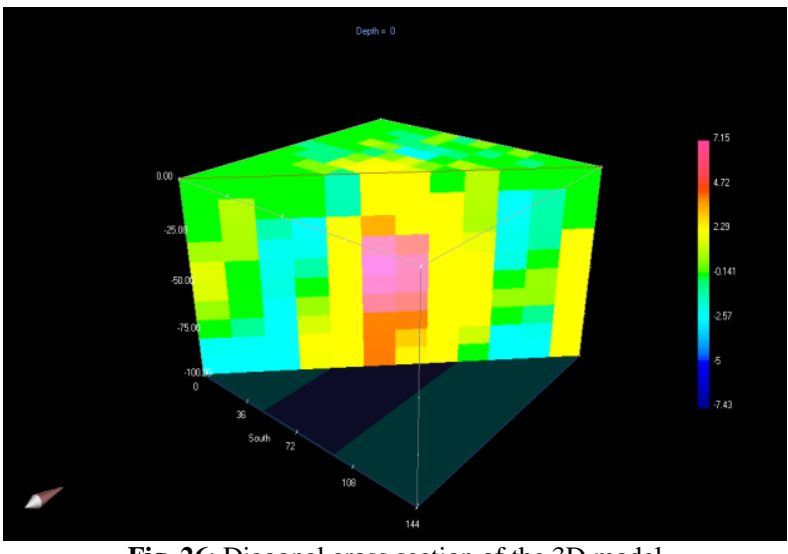

Fig. 26: Diagonal cross section of the 3D model

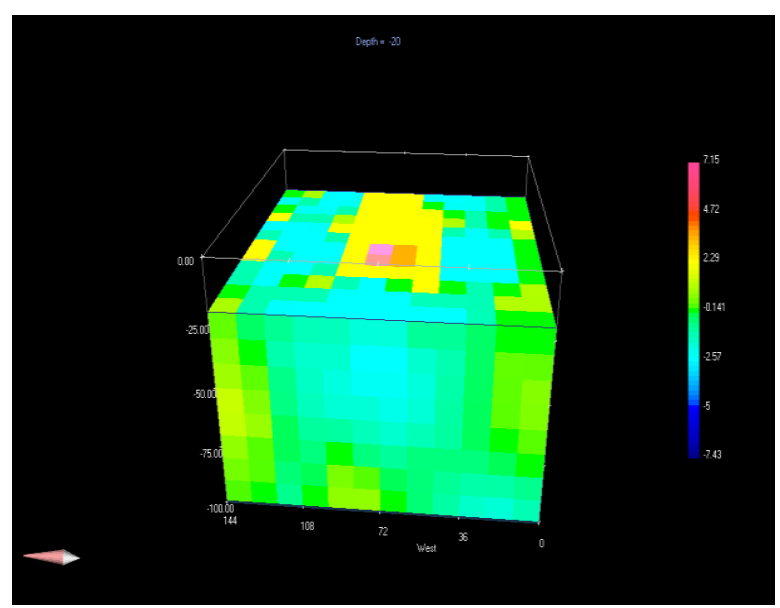

Fig. 27: Slice at 20m depth

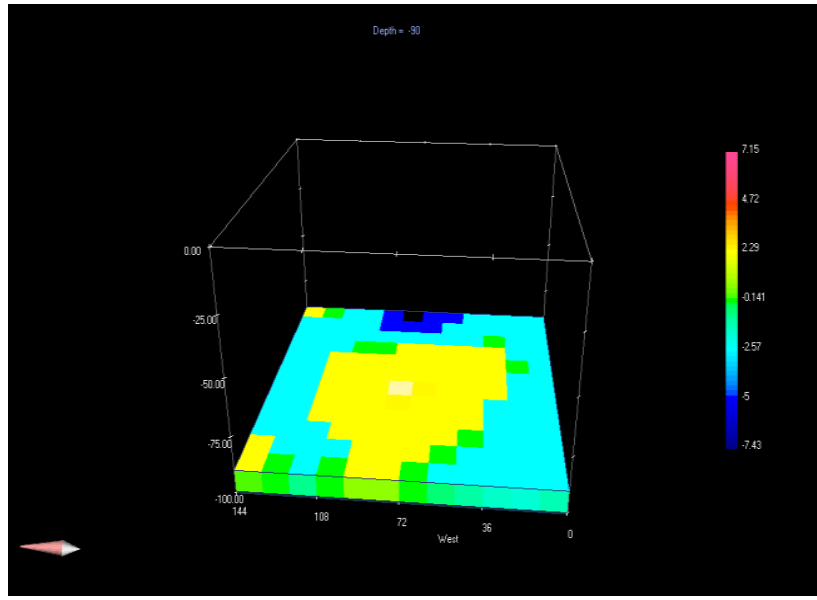

Fig. 28: Slice at 90m depth

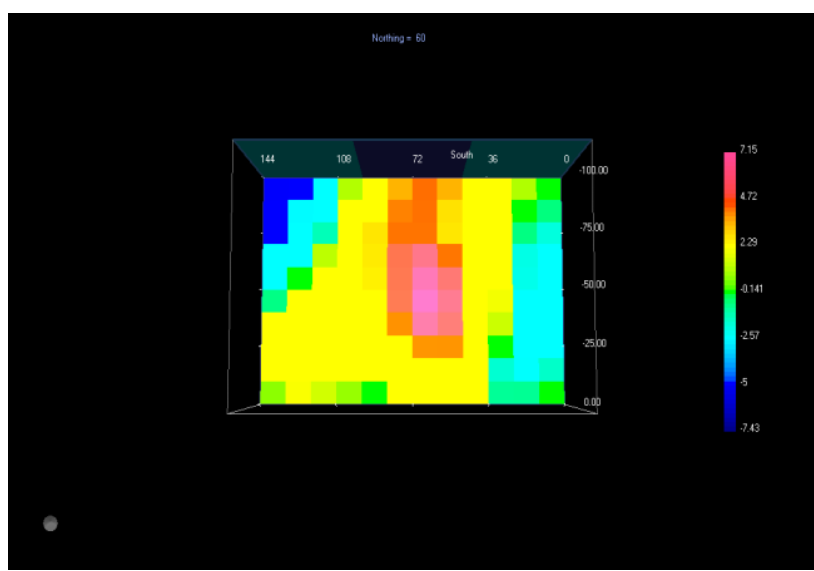

Fig. 29: Slice at 60m North

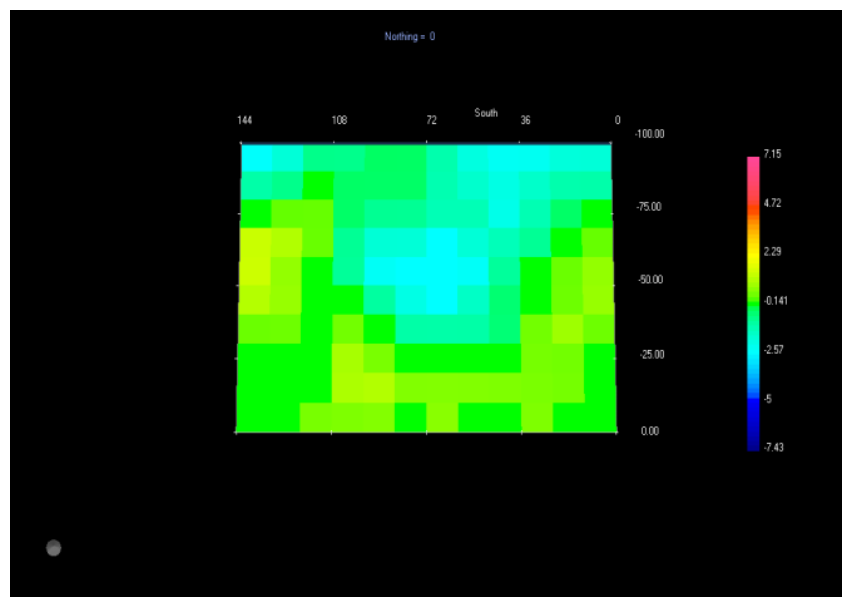

Fig. 30: Slice at $0 \mathrm{~m}$ North

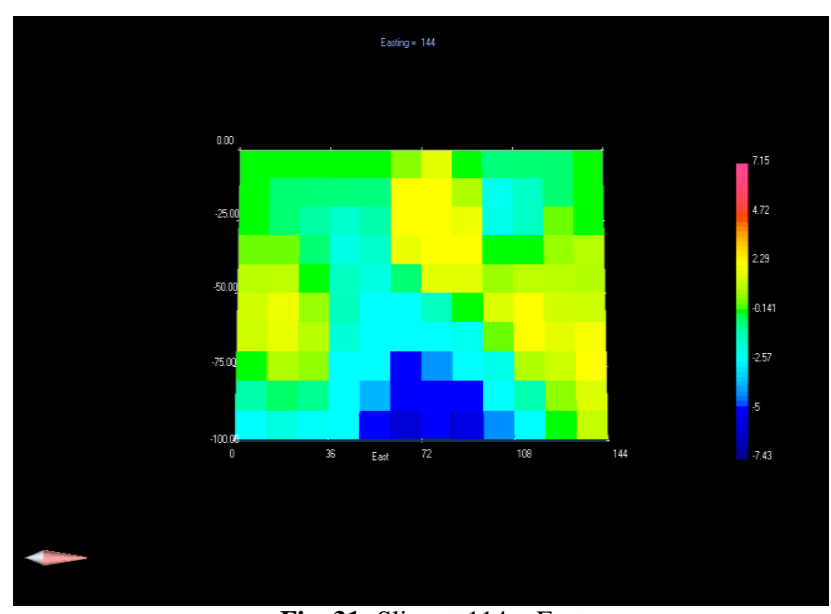

Fig. 31: Slice at $114 \mathrm{~m}$ East 


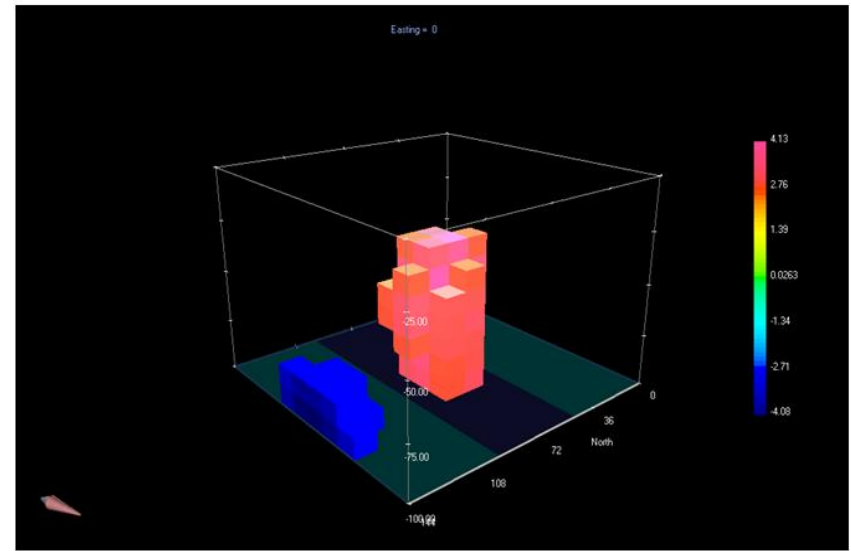

Fig. 32: An isosurface showing regions of highest and lowest magnetic susceptibility

\subsection{Discussion}

The 2D contour maps before and after subjecting it to drift and diurnal corrections were shown in figures 4 to 13 to compare the raw data with the processed data. The little variations observed in the $2 \mathrm{D}$ plots were as a result of diurnal variation of the earth's magnetic field and other sources of external interferences. The 3D contour maps (after subjecting it to drift and diurnal corrections) show the magnetic field intensity on each profile (fig. $14-23$ ) while 2D observed magnetic map (fig. 24) shows the raw "total field intensity" data of the study area. Filling the contour plots helps visualize the magnetic field variations on the study area and this greatly aid interpretation.

A visual inspection of the $2 \mathrm{D}$ observed magnetic map shows that the contour lines of the North-Western part of the map are widely spaced indicating that the depth to magnetic basement in these areas are relatively large. Whereas, from the centre to the SouthWestern part of the map, the contour lines are closely spaced indicating that the depth to the basement is shallow in this area. The closely spaced, linear sub parallel orientation of contours of the South-Western part of the map suggests the possibility of faults or local fractured zones passing through these areas (Kayode 2006). The magnetic signature obtained for the total component relative magnetic intensity plot along this traverse shows considerable varying amplitude from a minimum negative peak value of about $-89.68 \mathrm{nT}$ at a distance of about $90 \mathrm{~m}$ from the starting station to a maximum positive peak value of about $80.61 \mathrm{nT}$ at the centre of the study area. On the basis of the variation in magnetic intensity across the study area, there appears a general increase in magnetic intensity from the centre towards the South-Western region while a pronounced negative magnetic intensity at the North-Western region of the magnetic map. This variation is a function of the lithology of the basement complex.

Outcome of inversion (fig. 25) is a model of how magnetic susceptibility is distributed in the earth subsurface of the study area. Slices of the 3D model (fig. 26 - 31) show the susceptibility values of mineral rocks on the study area at different locations and depths. The 3D susceptibility model shows region of high magnetic susceptibility which indicates the presence of metallic mineral such as Coltan at a depth of about $20 \mathrm{~m}$ to $90 \mathrm{~m}$ located at the centre towards the southwestern part of the study area while region of low magnetic susceptibility values indicate the presence of mineral rocks such as Sandstone, Quartz and Calcite at a depth of about $75 \mathrm{~m}$ to $100 \mathrm{~m}$ located at $90 \mathrm{~m}$ due East from the first station.

To visualize the area with highest and lowest magnetic susceptibility, a 3D isosurface image was created (fig. 32). This is the display of regions with the same susceptibility values. Areas of highest (between 7.15 and 4.72) and lowest (between - 5.00 and 7.40) magnetic susceptibilities are only shown in this report and the blank space show regions of intermediate magnetic susceptibility values (between -4.00 and 4.00 ) which indicates the pres- ence of mineral rocks such as Tourmaline, Beryl and Mica in this study area.

\section{Conclusion}

Geomagnetic method has been used to investigate the locations and depths of magnetic rocks in the study area. The magnetic intensity anomaly maps of each profile and the observed magnetic data map have been shown. The 3D magnetic susceptibility model or inversion has been generated to show the distribution, location and depth of mineral rocks in the study area. The following conclusions could be made.

There were mineral rocks with high magnetic susceptibility at the centre towards the South Western part of the study area, and mineral rocks with low magnetic susceptibility at the North Western part of the study area.

The possible mineral rock buried in the region of high magnetic susceptibility values was Coltan while mineral rocks harboured in region of low magnetic susceptibility values were possibly Sandstone, Quartz and Calcite. More than fifty percentage of the volume has an intermediate magnetic susceptibility values and possibly haboured rocks such as Beryl, Mica and Tourmaline in massive and disseminated quantities.

From the 3D inversion of the study area, Coltan was located at the centre towards the South western region at a depth of about $20 \mathrm{~m}$ to $90 \mathrm{~m}$ while Quartz, Sandstone and Calcite were buried at a depth of about $75 \mathrm{~m}$ to $100 \mathrm{~m}$ (or more) located $90 \mathrm{~m}$ due East from the first station.

\section{Acknowledgement}

The authors acknowledge Mr. John Ogunmola for providing some useful literatures and software for this study.

\section{References}

[1] Adekoya, J. A., Kehinde-Phillips, O. O., Odukoya, A. M. (2003) Geological distribution of mineral resources in Southwestern Nigeria. Prospects for investment in mineral resources of Southwestern Nigeria A. A. Elueze (ed), Nigerian Mining and Geosciences Society (NMGS); pp. 1-13.

[2] Ahzegbobor, P. A. (2010): Acquisition geometry and inversion of 3D geoelectrical resistivity imaging data for environmental and engineering investigations. PhD thesis, Covenant University, Nigeria.

[3] Ajayi, T.R. and Ogedengbe, O. (2003): Opportunity for the Exploitation of Precious and Rare Metals in Nigeria. In: A.A. Elueze (Ed.), Prospects for Investment in Mineral Resources of Southwestern Nigeria, pp: 15-26.

[4] Al-chalabi, M., (1971): Some studies relating to non-uniqueness in the gravity and magnetic inverse problems. Geophysics 36, 835-854.

[5] Bhatacharyya, B.K., (1964): Magnetic anomalies due to prism-shaped bodies with arbitrary polarization. Geophysics 29, 517-531

[6] Constable, S. C., Parker, R.L. and Constable, C. G. (1987): Occam inversion: A practical algorithm for generating smooth models from electromagnetic sounding data. Geophysics, 54 p. 289-300

[7] Ellis, R. G. and Oldenburg, D. W. (1994): The pole-pole 3D DCresistivity inverse problem: a conjugate gradient approach. Geophysical Journal International, 119, p. 111-119.

[8] Folami, S.L., 1992. Interpretation of aero magnetic anomalies in Iwaraja area, southwesternNigeria Journal of Mining and Geology, 28(2): 391-396

[9] Ishola, K.S., Adeoti, L., Obianeri, A. (2012): Interpretation of the historic site, Agorin in Badagry, Southwestern Nigeria using geophysical methods. Ozean Journal of Applied Sciences 5(1), pp 85-99.

[10]Jain, S., (1976): An automatic method of direct interpretation of magnetic profiles. Geophysics 41, 531-541.

[11]Kayode, J.S., (2006): Ground magnetic study of Jeda-Iloko area, South-Western Nigeria and its geological implications. M.Tech. thesis Federal University of Techecnology, Akure, Nigeria.

[12] Kayode J. S. and Adelusi A.O. (2010): Ground Magnetic Data Interpretation of Ijebu-Jesa Area, Southwestern Nigeria, using Total Component. Research Journal of Applied Sciences, Engineering and Technology 2(8): 703-709. 
[13]Lelievre, P. G. and Oldenburg, D. W., (2006): Magnetic forward modelling and inversion for high susceptibility. Geophysical Journal International, vol. 166, pp76-90.

[14]Li, Y. and Oldenburg, D. W., (1996): 3-D inversion of magnetic data: Geophysics, 61, no. 02, $394-408$.

[15]Li, Y. and Oldenburg, D. W. (1998): Separation of regional and residual magnetic field data: Geophysics, 63, no. 02, 431-439.

[16]Li, Y., and D. W. Oldenburg (2003): Fast inversion of large-scale magnetic data using wavelet transforms and a logarithmic barrier method: Geophysical Journal International, 152, 251-265.

[17]National Geophysical Data Center's calculator, www.ngdc.noaa.gov/

[18]Nettleton, L.L., (1976): Gravity and magnetic in oil prospecting. McGraw-Hill, New York, pp $394-413$.

[19]Okunlola, O. A. and Ofonime, B. E. (2006): Geological setting, petrographical features and age of rare metal $(\mathrm{Ta}-\mathrm{Nb})$ mineralization of pegmatite of Komu area, Southwestern Nigeria. African Journal of Science and Technology (AJST); Science and Engineering Series; Vol. 7, No.1, pp.96-110.

[20]Olowofela, J. A., Akinyemi O. D. and Ogungbe, A. S. 2012. Imaging and Detecting Underground Contaminants in Landfill Sites Using Electrical Impedance Tomography (EIT): A Case Study of Lagos, Southwestern, Nigeria. Research Journal of Environmental and Earth Sciences 4(3): 270-281.

[21]Parasnis, D.S., (1978): Principles of Applied geophysics 3rd Ed. Chapmen and Hall, New York, USA, PP 103-110.

[22]Rahaman, M.A., (1976): Review of the basement geology of southwestern Nigeria In: Kogbe, C.A. (Ed); Geology of Nigeria. Elizabethan publishing co, Lagos pp, 41-58.

[23]Reijers T.J.A. (1996): Selected Chapters in geology, Shell Petroleum Development Company, Warri, Nigeria pp $87-90$.

[24]Shaw, R. and Srivastava, S. (2007): Particle swarm optimization: A new tool to invert geophysical data. Geophysics, 72 (2), p. F75-F83.

[25]Telford, W.M., Geldart, L.P. and Sheriff, R.E. (1990): Applied geophysics 3rd Edition, Cambridge University Press, Cambridge, pp 68110.

[26]Treitel, S. and Lines, L. (2001): Past, present and future of geophysical inversion - A new Millennium analysis, Geophysics, 66, pp 21 24

[27] Yang, X. and Labrecque, D. (1999): Comparison between Stochastic inversion and Occam inversion of 3D ERT data. Proceedings of the Symposium on the Application of Geophysics to Engineering and Environmental Problems, Oakland, CA, March 14-18. 